\title{
Configurality in judgment: Is it a bias?
}

\author{
YOAV GANZACH \\ Tel Aviv University, Tel Aviv, Israel
}

\begin{abstract}
Past research has shown that the relationship between cue and judgment often depends on the level of other cues (configural relationship). It is not clear, however, if this relationship is environmentally appropriate. To examine this issue, I compare configural models of the judgment with configural models of the criterion associated with this judgment. Two databases are analyzed. In one, the cues are the parents' educational level, the judgment is the educational expectations of the child, and the criterion is the actual educational achievement. In the other, the cues are the MMPI scores of psychiatric patients, the judgment is the clinical psychologists' estimation of the degree of pathology, and the criterion is the actual pathology. The analysis of both databases revealed that configurality characterizes the judgment but not the criterion.
\end{abstract}

The term configurality in judgment refers to a cuejudgment relationship in which the impact of a cue on the judgment depends on the level of other cues. Many studies have found configurality in judgment, primarily in two areas: subjective utility and social judgment. Thus, in integrating the values of possible outcomes of a lottery, the subjective weight of each outcome often depends on the values of the other outcomes (e.g., Luce \& Fishburn, 1990; Mellers, Chang, Birnbaum, \& Ordonez, 1992; Tversky \& Kahneman, 1992); and in integrating the values of various attributes of an object, the weight of each attribute depends on the values of the other attributes (e.g., Birnbaum \& Stegner, 1979; Skowronski \& Carlston, 1989).

The term configurality in the criterion refers to a cuecriterion relationship in which the impact of a cue on the criterion depends on the level of other cues. While many studies have examined configurality in judgment, only a handful have examined configurality in criteria, and none of them support the notion that important real-life criteria are configural (e.g., Dawes \& Corrigan, 1974; Goldberg, 1965).

The difference between previous studies concerning configurality in judgment and previous studies concerning configurality in the criterion suggests that configurality may be a characteristic of the judgment but not of the criterion. However, none of these previous studies asked whether configurality in judgment is environmentally appropriate. To answer this question, one needs to examine simultaneously whether configurality describes the relationships between cues and judgment and the relationships between cues and the criterion associated with the judgment. Thus, the major purpose of this paper is to compare configural aspects of judgments (e.g., judg-

The author would like to thank Yaacov Schul and Avi Kluger for many helpful discussions. Correspondence should be addressed to Y. Ganzach, Faculty of Management, Tel Aviv University, Tel Aviv, Israel, 69978 (e-mail: yoavgn@post.tau.ac.il). ment of behavior) with configural aspects of the criteria associated with them (e.g., actual behavior).

In the studies reported below, I examine examples that represent the most simple case of configural relationships, a case in which there are only two relevant cues (or group of cues), and the configural impact of one of them depends on the value of the other. When the cues are not correlated, these relationships can be modeled by the following equation:

$$
Y=\alpha+\beta_{1} X_{1}+\beta_{2} X_{2}+\delta X_{1} X_{2}
$$

where $Y$ is the dependent variable (judgment, criterion), and $X_{1}$ and $X_{2}$ are the relevant cues. This equation is a model of configurality since it implies that the weight of each of the two cues depends on the value of the other. The weight of $X_{1}$ is given by $\beta_{1}+\delta X_{2}$, and the weight of $X_{2}$ is given by $\beta_{2}+\delta X_{1}$. Note that, in this model, $\delta$ represents the extent of the configural relationships; therefore, the null hypothesis of nonconfigurality is $\delta=0$.

When $X_{1}$ and $X_{2}$ are correlated, the appropriate model for detecting configurality includes the quadratic terms of $X_{1}$ and $X_{2}$ :

$$
Y=\alpha+\beta_{1} X_{1}+\beta_{2} X_{2}+\gamma_{1} X_{1}^{2}+\gamma_{2} X_{2}^{2}+\delta X_{1} X_{2} .
$$

The reason for using this model is that, when there is a multicollinearity between $X_{1}$ and $X_{2}, X_{1} X_{2}$ is correlated with the quadratic terms. Therefore, if these terms are not included in the model, a significant coefficient may result from curvilinear relationships between the independent variables and the dependent variable and not from configurality (Lubinski \& Humphreys, 1990). ${ }^{1}$

\section{STUDY 1 \\ Educational Attainment Versus Educational Expectations}

In Study 1, I compare configurality in educational expectations to configurality in educational attainment, un- 
der the assumption that both the judgment (educational expectations) and the criterion (educational attainment) are determined, to a large extent, by the education of the parents. The reason for choosing this domain is the evidence suggesting configurality in judgments concerning academic success. In particular, in judging future academic success, people tend to assign a larger weight to the more positive information (Ganzach \& Krantz, 1991). Furthermore, the psychological antecedent of this configurality - an optimistic approach to the judgment taskseems to be associated with the psychological dimension of optimism-pessimism, which characterizes many other situations in which configurality in judgment has been observed (Weber, 1994).

\section{Data}

The data were taken from the National Longitudinal Survey of Youth (NLSY), a panel study conducted with a probability sample of 12,686 participants (oversampling of African-Americans, Hispanics, and economically disadvantaged whites) born between 1957 and 1964. Only participants who had both parents present at home when they were 14 years old participated in the analysis. Three variables from the 1979 survey are used in the current analysis: (1) the educational expectations of the youths, expressed in terms of the number of years of education they expect to complete, (2) the years of schooling achieved by the father, and (3) the years of schooling achieved by the mother. One variable was taken from the 1991 survey: the years of schooling achieved by the respondent. Thus, the judgment was obtained 12 years prior to measuring the criterion. Table 1 presents some descriptive statistics of these variables, as well as their intercorrelations.

\section{Analysis}

The model used in the analysis was:

$$
\begin{aligned}
Y= & \alpha+\beta_{1} \mathrm{ME}+\beta_{2} \mathrm{FE}+\gamma_{1} \mathrm{ME}^{2} \\
& +\gamma_{2} \mathrm{FE}^{2}+\delta(\mathrm{ME} * \mathrm{FE}),
\end{aligned}
$$

where the dependent variable, $Y$, is either educational expectations or educational attainment, FE is father's education, and ME is mother's education. Note that, in the judgment model, a negative value of $\delta$ indicates optimism, since it suggests that, when the education of one parent is low, the weight of the education of the other parent (whose education is not necessarily as low) is relatively high. Similarly, a positive value of $\delta$ indicates pessimism in the judgment.
Table 1

\begin{tabular}{lcccccc}
\multicolumn{7}{c}{ Descriptive Statistics of the NLSY Variables } \\
\hline & \multicolumn{7}{c}{ Intercorrelation } & & \\
& ME & FE & EE & EA & $M$ & $S D$ \\
\hline ME & 1.0 & .64 & .36 & .44 & 11.0 & 3.1 \\
FE & .64 & 1.0 & .38 & .45 & 11.0 & 3.9 \\
EE & .36 & .38 & 1.0 & .68 & 13.9 & 2.4 \\
EA & .44 & .45 & .68 & 1.0 & 13.9 & 2.4 \\
\hline
\end{tabular}

Note-ME, mother's education; FE, father's education; EE, educational expectations; EA, educational attainment.

The results of the educational attainment model and the educational expectations model are shown, respectively, at the foot of this page; EE stands for educational expectations, and EA stands for educational attainment (numbers in parentheses are standard errors of the estimates). In this analysis, the independent variables were centered around their mean in order to obtain meaningful coefficients of the linear terms (Cohen \& Cohen, 1983).

These results indicate that the process underlying these judgments of academic success is configural (and optimistic): In the judgment model, $\delta$ is significantly negative $[t(7,742)=3.8, p<.0001]$. On the other hand, there are no indications for configurality in the process underlying the criterion. In this model, $\delta$ is not significantly different from zero $[t(5,543)=1.3, p>.2] .^{2}$

It is interesting to note that, while the judgment and the criterion differ with regard to the nonlinearity associated with the configural relationships, they do not differ with regard to the nonlinearity associated with the curvilinear relationships. In both models, the curvilinear terms of mother's education and father's education are significantly positive $(p<.0001)$. Thus, nonlinearity in general may characterize both the judgment and the criterion, but configurality characterizes only the judgment.

To illustrate the differences between the judgment and the criterion, which were discussed above, the graphs of Figure 1 present the mean educational expectations and the mean educational attainment for each level of father's education, separately for high levels of mother's education (12 or more years) and low levels of mother's education (11 years or less). (Only levels of father's education for which there were enough available observations in each of the two levels of mother's education appear in the graphs.) The graphs show both the configural and the curvilinear relationships detected in the regressions. In particular, the graphs of educational expectations (Figure 1A) show both configural relationships (the distance between the curves decreases when father's education in-

$$
\begin{aligned}
& \mathrm{EA}=-.26+.233 * \mathrm{ME}+.177 * \mathrm{FE}+.014 * \mathrm{ME}^{2}+.012 * \mathrm{FE}^{2}-.005 *(\mathrm{ME} * \mathrm{FE}) \\
& \begin{array}{lllll}
(.04) & (.013) & (.010) & (.003) & (.002)
\end{array} \\
& R^{2}=.265 \\
& \mathrm{EE}=.228+.189 * \mathrm{ME}+.166 * \mathrm{FE}+.018 * \mathrm{ME}^{2}+.014 * \mathrm{FE}^{2}-.012 *(\mathrm{ME} * \mathrm{FE}) \\
& \begin{array}{lllll}
(.030) & (.011) & (.008) & (.002) & (.002)
\end{array} \\
& R^{2}=.208
\end{aligned}
$$




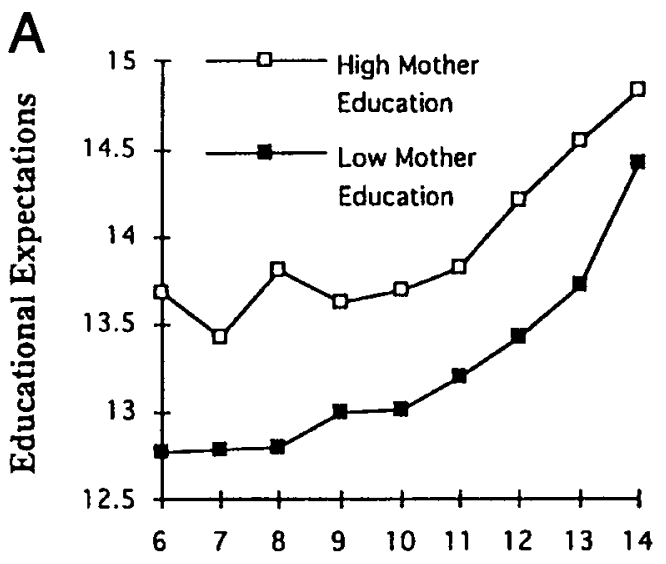

Father's Education

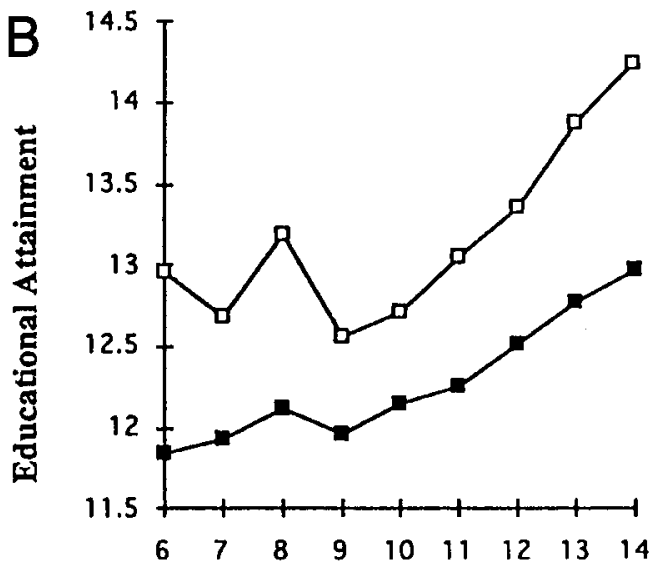

Father's Education

Figure 1. Mean educational expectations (A) and mean educational attainment (B) for each level of father's education, for high levels of mother's education (12 or more years) and low levels of mother's education (11 years or less).

creases) and curvilinear relationships, but the graphs of educational attainment (Figure 1B) show only curvilinear relationships.

\section{STUDY 2}

\section{Pathology Versus Judgment of Pathology}

In Study 2, I compare configurality in MMPI-based judgments of the degree of pathology of psychiatric patients with configurality in the actual diagnosis of pathology. The reason for choosing this domain is the evidence suggesting configurality in psychologists' judgments of pathology (Ganzach, 1995b). This configurality may be caused by clinical judgments that are based primarily on information associated with severe pathology (Renauld \& Estes, 1961; Rosenham, 1972).

\section{Data}

The data used were those collected by Paul Meehl on judgments concerning 861 patients, about half of whom were diagnosed as psychotic and half were diagnosed as neurotic, on the basis of their MMPI profiles (their scores on the 11 scales of the MMPI). The judgments were made by 29 clinical psychologists on an 11-step forced normal distribution from least psychotic (1) to most psychotic (11). The criterion was the hospital diagnosis of the patient, made primarily on the basis of direct observations of his or her behavior (see Meehl, 1959, for a detailed description of the data).

One aspect of the data that is particularly important to the present study is that the MMPI scales of the 861 profiles have a clear dimensional organization. One dimension is associated with the neurotic scales of the MMPI, another is associated with the psychotic scales, and a third dimension is associated with scales that identify defensiveness in test taking. These dimensions and, in particular, the neurotic and the psychotic dimensions played an important role in the process by which the clini- cians used the MMPI profiles in their diagnostic judgments in Meehl's experiment (Ganzach,1995b).

\section{Analysis}

The configural model used in the analysis was

$$
Y=\alpha+\Sigma \beta_{i} S_{i}+\gamma_{1} F_{1}^{2}+\gamma_{2} F_{2}^{2}+\delta\left(F_{1} * F_{2}\right),
$$

where the dependent variable $Y$ is either the judgment of pathology or the logarithm of the odds of the probability of a diagnosis of psychosis (since the criterion is dichotomous, a logistic model was used). $S_{i}$ is the test value of the $i$ th scale of the MMPI, and $F_{1}$ and $F_{2}$ are the unit weight values of the neurotic and psychotic dimensions, respectively (i.e., $F_{1}$ is the mean of the four neurotic scales, and $F_{2}$ is the mean of the five psychotic scales). In this model, the linear terms are those of the 11 MMPI scales rather than their dimensional representation, in order to allow for extracting the maximum linear variance prior to estimating the nonlinear effects (however, the results are very similar if the linear terms are those of the dimensions).

The results of the criterion model did not indicate any configurality: $\delta$ was not significantly different from zero $\left[\chi^{2}(1)=.002, p>.9\right] .^{3}$ On the other hand, the results of the model of the judgment did show configurality. In the model in which the dependent variable was the average judgment of the 29 clinicians, $\delta$ was significantly negative $[t(846)=7.0, p<.0001]$. The mean $\delta$ (over judges) was also significantly negative $[t(28)=13.9, p<.0001]$, and the models of the individual judges indicated that, for 21 of the 29 clinicians, $\delta$ was significantly negative $(p<.01){ }^{4}$

The differences between the judgment and the criterion are illustrated in Figure 2. Figure 2A presents the mean judgment of pathology as a function of the neurotic dimension and the psychotic dimension, using a median split on these dimensions. Figure 2B presents the percentage of patients diagnosed as psychotic. The graphs 

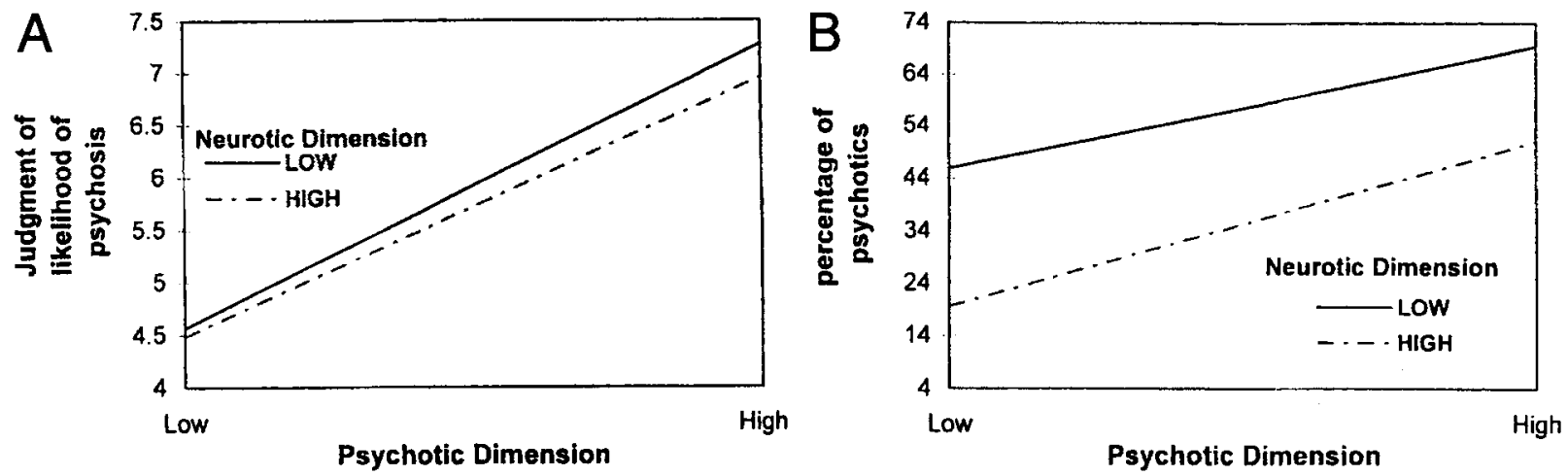

Figure 2. Mean judgment of the subjective likelihood of psychosis (A) and percentage of patients actually diagnosed as psychotics (B) as a function of the level of the psychotic and neurotic dimensions of the MMPI (using median splits on the two dimensions).

show that the relationship between the predictors and the judgment is configural, whereas the relationship between the predictors and the criterion is not configural. This configurality arises from the fact that the pathological information has an impact on judging the likelihood of psychosis versus neurosis both when it is present and when it is absent, whereas the nonpathological information has an impact only when it is present (see Fazio, Sherman, \& Herr, 1982, for a discussion of the differential impact of present vs. absent information on decision weight). In particular, the presence of pathological information (high levels on the psychotic dimension) is associated with a higher likelihood of psychosis, and the absence of this information (low levels on this dimension) is associated with a lower likelihood of psychosis. On the other hand, the presence of nonpathological information (high levels on the neurotic dimension) is associated with a lower likelihood of psychosis, whereas the absence of nonpathological information (low levels on the neurotic dimension) is not associated with a higher likelihood of psychosis. ${ }^{5}$

The curvilinear term of $F_{2}$ was not significant in the criterion model or in the judgment model, but the curvilinear term of $F_{1}$ was significantly positive in both models (in the model of the criterion, $p<.01$; in the model of the average judgment, $p<.0001$ ). The results of the models of the individual judges were quite similar to the results of the model of the average judgment; the mean curvilinear term of $F_{1}$ over judges was significantly positive $[t(28)=6.3, p<.0001]$. Thus, in these judgments, the curvilinear effects of the judgment are consistent with the curvilinear effects of the criterion.

\section{DISCUSSION}

Two databases from two different domains were analyzed in this paper. Bearing in mind that no systematic sampling of judgment domains was conducted (such a sampling is probably not even possible) and that only two databases were analyzed, the results of the analyses suggest that, configurality in judgment is a bias in that it occurs in the judgment but not in the criterion. The results also indicate similarities between the judgment and the criterion with regard to their curvilinear relationships with the cues. Thus, by and large, nonlinearity may characterize both the judgment and the criterion, whereas configurality characterizes only the judgment.
Why do people adhere to a configural strategy in a nonconfigural environment? One reason is motivational. Because of personal (Lopes, 1986) or situational (Birnbaum \& Stegner, 1979) motivational factors, they may be optimistic or pessimistic (e.g., Study 1; Quiggin, 1982), lenient or strict (e.g., Ganzach, 1993), or greedy or fearful (Lopes, 1987), and, therefore, they may assign more weight to positive or negative preces of information. A second reason is information-processing capabilities. Because of the difficulties of parallel processing, people may begin the process of generating a judgment using only one piece of information and form an interim judgment, which they then adjust on the basis of other pieces of information. If the tendency is to begin this process from the most positive (negative) information, and if adjustment is insufficient, configurality will result (Czaczkes \& Ganzach, 1996). A third reason is that configural theories about the relationships between independent and dependent variables may lead people to use configural judgment strategies. Thus, for example, clinical psychologists assign a heavier weight to the more pathological aspects of the information (Study 2), whereas social workers assign a heavier weight to the normal, or healthy, aspects of the information (Ganzach, 1994).

It could be argued that a configural judgment st rategy in a linear environment is not a bias if the goal of the judge is other than the minimization of judgment error. For example, Einhorn (1971) argued that configural strategy often results from assigning a higher weight to the more positive (negative) cue when the cost of false negative (false positive) is high (i.e., when people attempt to be lenient [strict] in their judgments). However, it is important to note that the high cost of false negative/positive is not a sufficient explanation for a configural strategy. For example, a high cost of false negative in the formation of educational expectations does not require assigning heavier weight to the more positive cues but rather an increase in the level of the judgment by a fixed amount. Similarly, a high cost of false positive in the evaluation of job candidates does not require assigning heavier weight to the more negative cues but rather the lowering of the evaluation by a fixed amount (Ganzach, 1993).

Finally, it is interesting to contrast cases such as the two presented in the present paper, in which the criterion is linear and the judgment is configural, to cases in which the criterion is configural and the judgment is linear. The latter cases occur in prediction experiments in which subjects are provided with configural feedback to their judgments (Brehmer, 1969; Edgell, 1978; Ganzach, 1995a; Mellers, 1980). In these experiments, the learning of the configural rules was rather difficult, and the strategy used at the onset of the experiment was linear. Why did people have such difficulty in learning configural strategies in these laboratory experiments, when this is the strategy they use in the natural environment? The reason is that, when feedback is supplied, the most natural strategy is one in which the extremity of the prediction is a weighted average of the extremity of the predictors - a strategy that leads to a linear combination of cues (Lichtenstein, Earle, \& Slovic, 1975). Thus, the presence of feedback may determine whether linear or configural strategies are used. 


\section{REFERENCES}

Birnbaum, M. H., \& Stegner, S. E. (1979). Source credibility in social judgment: Bias, expertise, and the judge's point of view. Journal of Personality \& Social Psychology, 37, 48-74.

BREHMER, B. (1969). Cognitive dependence on additive and configural cue-criterion relations. American Journal of Psychology, 82, 490-503.

COHEN, J., \& COHEN, P. (1983). Applied multiple regression/correlation for the behavioral sciences. Hillsdale, NJ: Erlbaum.

CzaczKes, B., \& Ganzach, Y. (1996). Preference reversal in equal probability gambles: A case for anchoring and adjustment. Journal of Behavioral Decision Making, 9, 5-140.

DAWES, R. M., \& CORRIGAN, B. (1974). Linear models in decision making. Psychological Bulletin, 81, 95-106.

EDGELL, S. E. (1978). Configural information processing in two cue nonmetric multiple-cue probability learning. Organizational Behavior \& Human Performance, 22, 404-416.

EDWARDS, J. R., \& VAN HARRISON, R. (1993). Job demands and worker health: Three dimensional reexamination of the relationship be tween person-environment fit and strain. Journal of Applied Psychology, 78, 628-648.

EINHORN, H. J. (1971). The use of nonlinear noncompensatory models as a function of task and amount of information. Organizational Behavior \& Human Performance, 6, 1-27.

Fazio, R. H., Sherman, S. J., \& Herr, P. M. (1982). The featurepositive effect in the self-perception process: Does not doing matter as much as doing? Journal of Personality \& Social Psychology, 42, 404-411.

GANZACH, Y. (1993). Goals as determinants of nonlinear, noncompensatory judgment strategies. Organizational Behavior \& Human Performance, 56, 422-440.

GANZACH, Y. (1994). Theory and configurality in expert and layman judgment. Journal of Applied Psychology, 79, 439-448.

GANZACH, Y. (1995a). The learning of natural configural strategies Organizational Behavior \& Human Decision Processes, 63, 195 206.

GANZACH, Y.(1995b). Nonlinear models of clinical judgment: Meehl's data revisited. Psychological Bulletin, 118, 422-429.

GanzaCH, Y., \& CzaczKes, B. (1995). On detecting nonlinear noncompensatory judgment strategies: Comparison of alternative regression models. Organizational Behavior \& Human Decision Processes, 68, 168-177.

GanZaCH, Y., \& KRANTZ, D. H. (1991). The psychology of moderate prediction: 1I. Leniency and uncertainty. Organizational Behavior \& Human Decision Processes, 48, 169-192.

GolDBERG, L. R. (1965). Diagnosticians vs. diagnostic signs: The diagnosis of psychosis vs. neurosis from the MMPI. Psychological Monographs, 79 (9, Whole No. 602)

Lichtenstein, S., Earle, T. C., \& Slovic, P. (1975). Cue utilization in a numerical prediction task. Journal of Experimental Psychology: Human Perception \& Performance, 104, 77-85.

LOPES, L. (1986). Reflection of preferences under risk: Who and when may suggest why. Journal of Experimental Psychology: Human Perception \& Performance, 12, 535-542.

LOPES, L. (1987). Between hope and fear: The psychology of risk. $A d-$ vances in Experimental Social Psychology, 20, (1987), 255-295.

LUBINSKI, D., \& HUMPHREYS, L. G. (1990). Assessing spurious "moderator effects": Illustrated substantively with the hypothesized ("synergistic") relation between spatial and mathematical ability. Psychological Bulletin, 107, 385-393.

LuCE, R. D., \& FishburN, P. C. (1990). Rank and sign-dependent linear utility models for finite first order gambles. Journal of Risk \& Uncertainty, 3, 229-241.

MEEHL, P. (1959). A comparison of clinicians with five statistical methods of identifying psychotic MMPI profiles. Journal of Counseling Psychology, 6, 102-109.

Mellers, B. A. (1980). Configurality in multiple-cue probability learning. American Journal of Psychology, 93, 429-443.
Mellers, B. A., Chang, S., Birnbaum, M., \& Ordonez, L. D. (1992). Preferences prices and rating in risky decision making. Journal of Experimental Psychology: Human Perception \& Performance, 18, 347-361.

QUIGGIN, J. (1982). A theory of anticipated utility. Journal of Economic Behavior \& Organization, 3, 323-343.

Renauld, H., \& Estes, F. (1961). Life history interview with one hundred normal American males: "Pathogenicity" of children. American Journal of Orthopsychiatry, 31, 786-802.

RosenHam, D. L. (1972). On being sane in insane places. Science, 179, 250-258.

Skowronski, J. J., \& CARLSTON, D. E. (1989). Negativity and extremity biases in impression formation. Psychological Bulletin, 105, 131-142.

TVERSKY, A., \& KAHNEMAN, D. (1992). Advances in prospect theory: Cumulative representation of uncertainty. Journal of Risk \& Uncertainty, 5, 297-323.

WEBER, E. U. (1994). From subjective probability to decision weights: The effect of asymmetric loss functions on the evaluation of uncertain outcomes and events. Psychological Bulletin, 115, 228-242.

\section{NOTES}

1. Why use a multiplicative function (and not other configural functions) to represent configurality? The reason for this is that the multiplicative function is likely to be a good representation of many judgment processes. In particular, it may be a good approximation of rank-dependent judgments - judgments in which the weight of a cue depends on its rank vis-à-vis the other cues. Note that while there are configural models that directly represent rank-dependent judgments (e.g., Birnbaum \& Stegner, 1979; Ganzach \& Czaczkes, 1995), in the presence of multicollinearity, there are statistical advantages for using a multiplicative function (Edwards \& Van Harrison, 1993).

2. Three technical points are worth noting. First, the two analyses vary in the number of observations, due to missing values of educational attainment. However, our findings do not appear to be sensitive to this variation. There is only a slight change in the results when the analyses are performed on a subset of the observations that have no missing values on any of the variables. Second, to examine the robustness of the effects, I added to the regressions other variables available in the NLSY, such as intelligence and household income, which were likely to have an important effect on the dependent variables. None of them had any substantial influence on the effects reported in the text. Third, to examine whether the difference between the interaction coefficient of the judgment model and the interaction coefficient of the criterion model is significant, I performed a repeated measures analysis, where the judgment and the criterion were the two levels of the repeated factor. This analysis indicated a significant interaction between the repeated factor and the interaction term $(p<.01)$.

3. To ascertain that the interaction does not depend on the logistic transformation of the dependent variable, a linear probability model (i.e., a model in which the dependent variable was the probability of a diagnosis of psychosis) was also examined. The results of this model were similar to the results of the logistic model.

4. The parameter estimates (standard errors of the estimates) of the curvilinear effect of the neurotic dimension, the curvilinear effect of the psychotic dimension, and the interaction were, respectively, .0016 (.0002), $.0001(.0003)$, and -.0025 in the average judgment model, and $.0015(.0006), .0014(.0012)$, and $.00006(.0014)$ in the criterion model (in this model, psychotic was coded as 1 and neurotic as 0 ).

5 . The graphs also indicate that the judgments are based primarily on pathological information, since, in the judgment, the linear effect of the psychotic dimension is much larger than the linear effect of the neurotic dimension, whereas, in the criterion model, the two effects are about the same.

(Manuscript received June 6, 1996; revision accepted for publication December 8,1996 .) 